\title{
COLOR STABILITY OF EMAX CAD LAMINATE VENEERS CEMENTED WITH LIGHT CURE VERSUS DUAL CURE AMINE FREE ADHESIVE RESIN CEMENT (RANDOMIZED CONTROLLED CLINICAL TRIAL)
}

\author{
Mahmoud Elkomy *, Jylan El-guindy ${ }^{* *}$ and Maha Taymour ${ }^{* * *}$
}

\begin{abstract}
Statement of the problem The increased thickness of ceramic laminate veneer with butt joint design at the incisal edge reduce the amount of light reaching the cement layer and therefore compromise photo-activation of the luting material However, an adequate cure of the resin-based cement is an important prerequisite for the stability and biocompatibility of the restoration. ${ }^{57}$ Dual-cure resin-based cements have been recommended for luting ceramic laminate veneers to compensate for the attenuation of the curing light effected by the thickness of restoration and to allow complete polymerization of the luting material even at the incisal area of laminate veneers where access for the curing light is limited, but the yellowish discoloration due to ageing of conventional dual-cure resin based cement was the problem.
\end{abstract}

Purpose : The aim of this study was to evaluate color stability of e-max CAD veneers cemented with light cure and dual cure amine free adhesive resin cement (Base line), (After 2 months), (After 4 months), (After 6 months),(After $8 \mathrm{~m}$ )

Materials and methods: A total of 22 ceramic laminate veneers restorations(11 e.max cad cemented with light cure adhesive resin cement and 11 e.maxcad cemented with dual cure adhesive resin cement ) were included in the study and completed by one operator (the researcher) who followed a meticulous clinical procedure and the ceramic laminate veneers were fabricated by one experienced dental technician. The operator followed the five phases of laminate veneers fabrication: diagnosis, preparation design, provisionalization , construction of the material and bonding ,Follow up sessions were done every two month for each patient using operator vision to evaluated change in color and then confirmed with easyshade in the baseline, 24 hours post cementation and in the postoperative follow-up according to the modified USPHS (United States Public Health Service) criteria. This was performed by an experienced, blinded investigator. Data were recorded, tabulated, and statistically analyzed using the Chi-square test and the significance level was set at $\mathrm{P} \leq 0.05$.

Results: There was no statistically significant difference between (Group I) and (Group II) where $(\mathrm{p}=1)$ as both groups showed $(100 \%)$ Alpha in all time periods.

Conclusion: Both E.max CAD laminate veneers cemented with light cure and E.max CAD laminate veneers cemented with dual cure amine free adhesive resin cement revealed high successful survival rate in terms of the stability of the color.

Keywords: E.max CAD, Amine free, duel cure, light cure, Laminate veneers, color stability, Bonding, cementation.

* Dentist at Ministry of health, Egypt.

** Professor at Fixed Prosthodontics Department, Faculty of Dentistry, Cairo University, Egypt and Vice Dean of NUB faculty of oral \& dental medicine.

*** Professor at Fixed Prosthodontics Department, Faculty of Dentistry, Cairo University, Egypt. 


\section{INTRODUCTION}

Ceramic laminate veneer (CLV) restorations have gained increasing popularity for esthetic improvement of anterior teeth. CLVs have been reported a durable and conservative restorations with superior esthetics. ${ }^{1}$

The luting agents available for ceramic restorations can be auto-, light- or dual- polymerizing resin cement. In vitro studies have indicated that dualpolymerizing resin cements undergo greater color alteration than lightpolymerizing cements, which is usually attributed to the oxidation of aromatic tertiary amines present on the dual cements as accelerators of the auto polymerizing reaction. The presence of unreacted double bonds, composition ofmonomers used in the matrix, filler size and content, water absorption, and environmental factors may also cause color instability in resin cements. ${ }^{2,3}$

The purpose of the different shades of resin cements is to achieve clinically acceptable estorations with good color matching to the adjacent dentition.

However, the final color of translucent ceramic restorations is determined by the thickness of the porcelain and luting agent as well as the color of the luting agent and the underlying tooth structure. ${ }^{4}$

\section{MATERIALS AND METHODS}

Sample size calculation Sample size calculation: If there was truly no difference between the standard and experimental treatment, then 16 restorations were required to be $80 \%$ sure that the limits of a two-sided $90 \%$ confidence interval would exclude a difference between 2 groups of more than $15 \%$. This number was increased to 20 to compensate for losses during follow up. 5

Research ethics approval: This study and the template informed consent form reviewed by the Ethics Committee of Scientific Research - faculty of Dentistry - Cairo University and approved in December 2016.
Study design: This study was performed in Fixed Prosthodontics Department clinics of Faculty of Dentistry, Cairo University, Cairo, Egypt. A total of 22 ceramic laminate veneers were included in the study and completed by one operator (the researcher). A total of four patients (2 patients in each group) were selected for the study with an age range between 20 to 50 years old.

\section{Patients were selected as follows:}

Inclusion criteria were: 1. Age: $18-40$ years old, able to read and sign the informed consent document. 2. Physically and psychologically able to tolerate conventional restorative procedures. 3. Have no active periodontal or pulpal diseases. 4. Have teeth with good restorations. 5. Patients with teeth problems indicated for laminate veneer (e.g. discoloration, fracture not involving more than $50 \%$ enamel loss, mild malposition, upper anterior ,spacing). 6. willing to return for follow-up examinations and evaluation.

Exclusion criteria were: 1. Patients in the growth stage with partially erupted teeth. 2 . Patient with fractured teeth of more than $50 \%$ enamel loss. 3 . Patients with poor oral hygiene and motivation. 4. Pregnant women. 5. Psychiatric problems or unrealistic expectations. 6. Lack of opposite occluding dentition in the area intended for restoration.

Randomization: The patients were randomly divided into 2 groups using web site (WWW.RANDOM.ORG) into 2 equal groups.

Blinding: The investigators and the statistician were blind throughout the whole procedures and follow-up visits.

Group allocation: The 4 patients were divided into 2 groups, 2 patients in each group: Group (1) control group: included 2 patients each patient received 6 e.max Cad laminate veneers cemented with bisco light cured adhesive resin cement on the 
upper six anterior incisors with Butt joint bonded with delayed bonding technique. Group (2) intervention group: included 2 patients each patient received 6 e.max cad laminate veneers cemented with Nexus third generation dual cure adhesive resin cement on the upper six anterior incisors with Butt joint bonded with delayed bonding technique.

I- Diagnostic phase: Intra-oral examination, photographs, diagnostic casts, diagnostic wax up, scaling, polishing and shade selection were performed.

\section{II- Tooth preparation phase:}

1- Silicon matrix construction for preparation index: A putty silicon was used to obtain index for each patient using rubber base impression material.

2- The labial preparation: The labial reduction was started with horizontal orientation grooves using depth cutter wheels. Labial reduction was $0.5 \mathrm{~mm}$ at the cervical third and $0.7 \mathrm{~mm}$ at the middle and incisal thirds. 3-Incisal preparation: Vertical orientation grooves were done on the incisal edge of the tooth. The tapered stone with round end diamond stone was placed parallel to the incisal edge to remove the projection between grooves resulting in $2 \mathrm{~mm}$ butt joint incisal preparation.

4- Cervical finish line: The cervical margin was created supra-gingivally along the free gingival margin.

5- Proximal extension: Due to presence of spacing in all the selected cases, the interproximal preparation was extended beyond the contact areas.

6- Finishing the preparation

III-Impression making phase: Final impression were taken using addition silicon (Panasil, Kettenbach, Germany) in stock trays. Two step impression technique was done.
IV-Provisionalization: was constructed using bisacrylate composite resin material (Dento Crown. ITENA, France).

V- eneer fabrication: Started by scanning the master cast, designing of the final restoration and finally starting the milling process: Using 5-axis milling machine followed by short firing cycle to complete the crystallization process.

VI: Bonding of laminate veneers: The fitting surface of the ceramic veneers were etched for 20 seconds with 9.5\% hydrofluoric acid (Bisco ceramic etch ,U.S.A). The veneers were rinsed with water for 20 seconds then dried with air. Then a single coat of the ceramic primer was then applied to the bonding surface of the veneers and left for 1 minute then excess is air dried.

Finally surfaces were dried gently for 5 seconds and the veneers of intervention group were cemented in place with dual cure Nexus 3 adhesive resin cement where the cement applied to the fitting surface of laminates using auto mix tip where the control group cemented with bisco light cure resin cement. The cementation steps were done individually from the midline in the following order: two centrals, lateral incisors then the canine. excess cement was removed using sharp explorer after 5 seconds of preliminary light polymerization and the restoration were then completely light polymerization with an energy density of $480 \mathrm{~mW} / \mathrm{cm}$ for at least 40 seconds from each aspects of the tooth. An articulating paper was used to establish appropriate occlusal contacts. Contacts were tested with floss and adjusted with diamond bur and ceramic polishing burs

\section{Follow up sessions:}

Follow up sessions were done every three months for each patient using dental probe and direct vision to evaluate the outcome according to USPHS criteria (United States Public Health Service). 
TABLE (1): Summary of the modified United States Public Health Service criteria6

\begin{tabular}{|c|c|c|c|}
\hline Characteristics & Alpha (A) & Bravo $\underline{(\mathrm{B})}$ & $\begin{array}{c}\text { Charlie } \\
(\mathrm{C})\end{array}$ \\
\hline $\begin{array}{c}\text { Color change } \\
\text { of restoration }\end{array}$ & $\begin{array}{c}\text { No } \\
\text { change }\end{array}$ & $\begin{array}{c}\text { Change of color } \\
\text { according to base- } \\
\text { line condition }\end{array}$ & N/A \\
\hline
\end{tabular}

* N/A: not applicable

\section{No Patient attrition:}

During follow up period, all patients attended in the control group and the intervention group. Data were recorded, tabulated then statistically analyzed.

\section{Statistical methods}

All Data was collected, checked, revised, tabulated and entered into the computer. They were analyzed using IBM SPSS advanced statistics (Statistical Package for Social Sciences), version 20 (SPSS Inc, Chicago, IL). Categorical data were described as numbers and percentages. Comparisons between categorical variables will be performed using the chi square test or fisher exact as appropriate. A pvalue less than or equal to 0.05 was considered statistically significant. All tests were two tailed. ${ }^{5}$

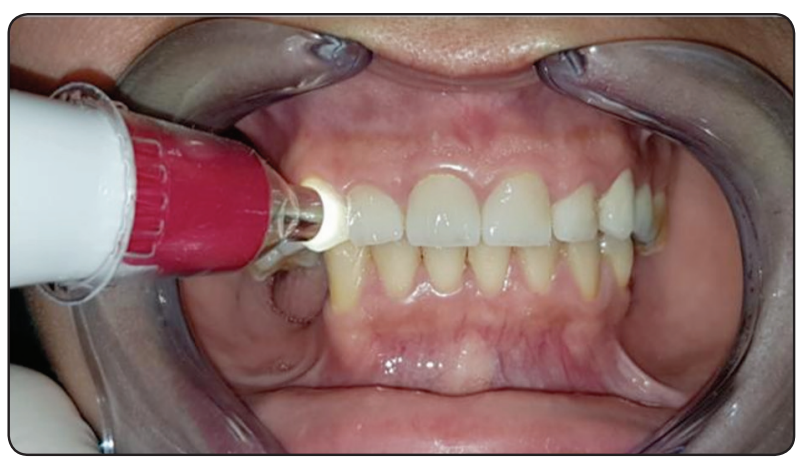

Fig. (1) Post-operative evaluation of color by easy shade

\section{RESULTS}

The mean and standard deviation values were calculated for each group in each test. Data were explored for normality using Kolmogorov-Smirnov and Shapiro-Wilk tests, data showed non- parametric (not normal) distribution. The data obtained by evaluating each assessment criteria were statistically analyzed using the Chi-square test. The significance level was set at $\mathrm{P} \leq 0.05$. Statistical analysis was performed with IBM ${ }^{\circledR}$ SPSS $₫$ Statistics Version 20 for Windows.

1. Color change (visual): Descriptive statistical analysis presented in table (6) figure (55) revealed the following: According to modified USPHS criteria in color change evaluation:

a) Group I (e.max cad cemented with bisco light cure adhesive resin cement):

There was no statistically significant difference between (Base line), (After 2 months), (After 4 months), (After 6 months),(After 8 months),(after8 months) and (After 12 months) where ( $\mathrm{p}=1)$.

Alpha grade was recorded for all the veneers at all the intervals of evaluation and none of samples were Charlie.

b) Group II (e.max cad cemented with Nexus third generation dual cure adhesive resin cement):

There was no statistically significant difference between (Base line), (After 3 months), (After 6 months), (After 9 months) and (After 12 months) where $(p=1)$.

Alpha grade was recorded for all the veneers at all the intervals of evaluation and none of samples were Charlie.

\section{Relation between both groups:}

There was no statistically significant difference between (Group I) and (Group II) both groups showed no color change in 2,4,6,12 month follow up period 
TABLE (2): The frequencies of Alpha, Bravo and Charlie of different groups for marginal adaptation

\begin{tabular}{|c|c|c|c|c|c|c|}
\hline \multicolumn{2}{|c|}{ Variables } & \multicolumn{5}{|c|}{ Color change (yea/no) visual } \\
\hline & & \multicolumn{2}{|c|}{$\begin{array}{l}\text { Group I (e.max cad cemented with } \\
\text { Nexus third generation dual cure } \\
\text { adhesive resin cement) }\end{array}$} & \multicolumn{2}{|c|}{$\begin{array}{l}\text { Group II (Emascad cemented with } \\
\text { Nexus third generation dual cure } \\
\text { adhesive resin cement): }\end{array}$} & \multirow[t]{2}{*}{ P-value } \\
\hline & & $\mathrm{N}$ & $\%$ & $\mathrm{~N}$ & $\%$ & \\
\hline \multirow[t]{3}{*}{ Base line } & Alpha & 11 & $100 \%$ & 11 & $100 \%$ & \multirow[t]{3}{*}{1} \\
\hline & Brave & 0 & $0 \%$ & 0 & $0 \%$ & \\
\hline & Charlie & 0 & $0 \%$ & 0 & $0 \%$ & \\
\hline \multirow[t]{3}{*}{ After 2 months } & Alpha & 11 & $100 \%$ & 11 & $100 \%$ & \multirow[t]{3}{*}{1} \\
\hline & Brave & 0 & $0 \%$ & 0 & $0 \%$ & \\
\hline & Charlie & 0 & $0 \%$ & 0 & $0 \%$ & \\
\hline \multirow[t]{3}{*}{ After 2 months } & Alpha & 11 & $100 \%$ & 11 & $100 \%$ & \multirow[t]{3}{*}{1} \\
\hline & Brave & 0 & $0 \%$ & 0 & $0 \%$ & \\
\hline & Charlie & 0 & $0 \%$ & 0 & $0 \%$ & \\
\hline \multirow[t]{3}{*}{ After 6 months } & Alpha & 11 & $100 \%$ & 11 & $100 \%$ & \multirow[t]{3}{*}{1} \\
\hline & Brave & 0 & $0 \%$ & 0 & $0 \%$ & \\
\hline & Charlie & 0 & $0 \%$ & 0 & $0 \%$ & \\
\hline \multirow[t]{3}{*}{ After 8 months } & Alpha & 11 & $100 \%$ & 11 & $100 \%$ & \multirow[t]{3}{*}{1} \\
\hline & Brave & 0 & $0 \%$ & 0 & $0 \%$ & \\
\hline & Charlie & 0 & $0 \%$ & 0 & $0 \%$ & \\
\hline \multirow{3}{*}{$\begin{array}{l}\text { After } 10 \\
\text { months }\end{array}$} & Alpha & 11 & $100 \%$ & 11 & $100 \%$ & \multirow[t]{3}{*}{1} \\
\hline & Brave & 0 & $0 \%$ & 0 & $0 \%$ & \\
\hline & Charlie & 0 & $0 \%$ & 0 & $0 \%$ & \\
\hline \multirow{3}{*}{$\begin{array}{l}\text { After } 12 \\
\text { months }\end{array}$} & Alpha & 11 & $100 \%$ & 11 & $100 \%$ & \multirow[t]{3}{*}{1} \\
\hline & Brave & 0 & $0 \%$ & 0 & $0 \%$ & \\
\hline & Charlie & 0 & $0 \%$ & 0 & $0 \%$ & \\
\hline \multicolumn{2}{|c|}{ P-value } & \multicolumn{2}{|c|}{1} & \multicolumn{2}{|c|}{1} & \\
\hline
\end{tabular}

\section{DISCUSSION}

This study was a randomized, double blinded clinical trial to eliminate the risk of selection bias of the included patients. Since the main investigator performed all the procedures during this study, then, the evaluation of the outcomes had to be done by an experienced professor who was blinded and did not know the patients belonged to which group. Also, the statistician was blinded during the analysis of the results of this study.

Ceramic laminate veneers are considered a conservative modality that provides excellent potential for esthetic enhancement. Veneer preparation preserve sound tooth structure which is the ultimate 
goal of the minimally invasive veneer preparation. ${ }^{7}$ Anterior teeth were chosen for this study as they are the most commonly restored teeth with ceramic laminate veneers, their presence in the esthetic zone and to standardize bonding area of all restorations. ${ }^{8}$

It has been suggested that a maximum of $0.5 \mathrm{~mm}$ thickness to be done at the cervical region of labial veneer preparation. ${ }^{9}$ In order to standardize our preparation design three wheels depth cutter was used to have minimum depth cutting. Then, silicon index was performed for checking final preparation depth and design. ${ }^{10,11}$

All labial preparation of all teeth was prepared with chamfer finish line, located $1 \mathrm{~mm}$ supragingival labially to make sure that all margins were within enamel, thus enhancing the bond between enamel and adhesive resin cement which will decrease the chances of marginal microleakage and deteriorations. ${ }^{12,13}$ The final impression was taken with addition silicon impression material since it has low dimensional change, relatively short setting time and with moderate to high tear resistance. ${ }^{14}$

In this study ceramic laminate veneers were fabricated from: Lithium disilicate ceramic (e.max CAD). Since it has been considered the strongest glass-ceramic, have high number of microstructural, interlocking, needle-like lithium disilicate crystals embedded in a glassy matrix. Lithium disilicate ceramic (e.max CAD) have high mechanical properties than other types of glass based ceramic materials. ${ }^{15,16}$

Laminate veneers in this study were treated with hydrofluoric acid, as the microstructure of the ceramic is changed by hydrofluoric acid attack of the glassy phases of dental porcelain. Because the ceramic has components bondable to silane such as silica, the bonding process can be enhanced by application of silane coupling agent. ${ }^{17}$

Dual-cure resin-based cements have been recommended for luting ceramic laminate veneers to compensate for the attenuation of the curing light affected by the thickness of restoration and to allow complete polymerization of the luting material even at the incisal area of laminate veneers where access for the curing light is limited. ${ }^{18}$

Bisco Choice 2 light cure resin cement was the cement of choice in our study. It has a polymerization mechanism that only allows material setting in the presence of a light source that activates photo- initiators to start the polymerization reaction. The advantage of these materials is their ease of use due to their controlled setting time and the unlimited working time. ${ }^{19}$ Color change results: The Alpha score of no color change was recorded for all veneers. Invitro study by Çağn Ural et al 2016 showed that the color change of both light cure and dual cure adhesive resin cement were within clinically accepted level also, third-generation adhesive resin cements with free tertiary amines and benzoyl peroxide underwent smaller color changes than the light- and dual-cure resin materials ${ }^{3}$ Marchionatti et al 2017 concluded that The light- and dualpolymerizing modes presented similar color changes for all evaluated periods (2, 6, 12, and 24 months). ${ }^{20}$ Also, Ah-Rang Kim, et al 2015 said that the color change of selfcure and dual cure adhesive resin cement caused by the amine group ${ }^{21}$ Also, Evren Kilinc et al 2011 concluded that all resin cements did not cause a noticeable color change on the ceramic, which also showed that even a significant color change of the resin cement may be unnoticeable when covered by the ceramic. ${ }^{2}$

\section{CONCLUSIONS}

Both E.max CAD laminate veneers cemented with light cure and E.max CAD laminate veneers cemented with dual cure amine free adhesive resin cement revealed high successful survival rate in terms of the stability of the color. Therefore dual cure amine free adhesive resin cement can be considered a good alternative for cementation of laminate veneers. 


\section{REFERENCES}

1. Shetty, et al.: Survival rates of porcelain laminate restoration Journal of Conservative Dentistry | Jan-Mar 2011 | Vol 14

2. Kilinc E, Antonson SA, Hardigan PC, Kesercioglu A. Resin cement color stability and its influence on the final shade of all-ceramics. Journal of dentistry. 2011 Jul 1;39:e30-6.

3. Ural Ç, Duran İ, Tatar N, Öztürk Ö, Kaya İ, Kavut İ. The effect of amine-free initiator system and the polymerization type on color stability of resin cements. Journal of oral science. 2016;58(2):157-61.

4. de Magalhães AP, de Siqueira PC, de Carvalho Cardoso P, de Souza JB, Fonseca RB, Lopes LG. Influence of the resin cement color on the shade of porcelain veneers after accelerated artificial aging. Revista Odontológica do Brasil Central. 2013 May 7;22(60).

5. Julious, S. A. Sample sizes for clinical trials. CRC Press. 2009.

6. Bayne, S. C., \& Schmalz, G. Reprinting the classic article on USPHS evaluation methods for measuring the clinical research performance of restorative materials. Clinical oral investigations. 2005. 9(4), 209-214.

7. Lerner JM. Conservative Aesthetic (2006) Enhancement of the Maxillary Anterior Using Porcelain Laminate Veneers. Pract Proced Aesthetic Dent.;18(6):361-366.

8. Cherukara, G. P., Seymour, K. G., Samarawickrama, D. Y. D., \& Zou, L. (2002). A study into the variations in the labial reduction of teeth prepared to receive porcelain veneers-a comparison of three clinical techniques. British dental journal, 192(7), 401.

9. Vanlığlu BA, Kulak-Özkan Y. (2014) Minimally invasive veneers: current state of the art. Clin Cosmet Investig Dent.;6:101-107. doi:10.2147/CCIDE.S53209.

10. Magne, P., \& Belser, U. (2002). Bonded porcelain restorations in the anterior dentition: a biomimetic approach. Quintessence Publishing Company.

11. Brunton, P. A., Aminian, A., \& Wilson, N. H. F. (2000). Restorative dentistry: Tooth preparation techniques for porcelain laminate veneers. British dental journal, 189(5), 260.

12. Guess, P. C., Vagkopoulou, T., Zhang, Y., Wolkewitz, M., \& Strub, J. R. (2014). Marginal and internal fit of heat pressed versus CAD/CAM fabricated all-ceramic onlays after exposure to thermo-mechanical fatigue. Journal of dentistry, 42(2), 199-209.

13. Kumari, N., \& Nandeeshwar, D. B. (2015). The dimensional accuracy of polyvinyl siloxane impression materials using two different impression techniques: An in vitro study. The Journal of the Indian Prosthodontic Society, 15(3), 211.

14. Fradeani, M., Redemagni, M., \& Corrado, M. (2005). Porcelain laminate veneers: 6-to 12-year clinical evaluation--a retrospective study. International journal of periodontics \& restorative dentistry, 25(1).

15. Al-Akhali, M., Chaar, M. S., Elsayed, A., Samran, A., \& Kern, M. (2017). Fracture resistance of ceramic and polymer-based occlusal veneer restorations. Journal of the mechanical behavior of biomedical materials, 74, 245-250.

16. Coldea, A., Swain, M. V., \& Thiel, N. (2013). In-vitro strength degradation of dental ceramics and novel PICN material by sharp indentation. Journal of the mechanical behavior of biomedical materials, 26, 34-42

17. Ercan, E., Dülgergil, Ç. T., Soyman, M., Dalli, M., \& Yildirim, I. (2009). A field-trial of two restorative materials used with atraumatic restorative treatment in rural Turkey: 24- month results. Journal of Applied Oral Science, 17(4), 307-314.

18. Uctasli S, Hasanreisoglu U, Wilson HJ. The attenuation of radiation by porcelain and its effect on polymerization of resin cements. Journal of Oral Rehabilitation. 1994 Sep 1;21(5):565-75.

19. Kumari N, Nandeeshwar DB. The dimensional accuracy of polyvinyl siloxane impression materials using two different impression techniques: An in vitro study. The Journal of the Indian Prosthodontic Society. 2015 Jul;15(3):211.

20. Marchionatti AM, Wandscher VF, May MM, Bottino MA, May LG. Color stability of ceramic laminate veneers cemented with light-polymerizing and dual-polymerizing luting agent: A split-mouth randomized clinical trial. Journal of Prosthetic Dentistry. 2017 Nov 1;118(5):604-10.

21. Kim AR, Jeon YC, Jeong CM, Yun MJ, Huh JB. Effect of Accelerated Aging on the Color Stability of Dual-Cured Self-Adhesive Resin Cements. Journal of Korean Dental Science. 2015 Dec 1;8(2):49-56. 